\title{
Skutterudite thermoelectric modules with high volume-power-density: scalability and reproducibility
}

Article

Accepted Version

Prado-Gonjal, J., Phillips, M., Vaqueiro, P., Min, G. and Powell, A. V. (2018) Skutterudite thermoelectric modules with high volume-power-density: scalability and reproducibility. ACS Applied Energy Materials, 1 (11). pp. 6609-6618. ISSN 25740962 doi: https://doi.org/10.1021/acsaem.8b01548 Available at https://centaur.reading.ac.uk/80527/

It is advisable to refer to the publisher's version if you intend to cite from the work. See Guidance on citing.

To link to this article DOI: http://dx.doi.org/10.1021/acsaem.8b01548

Publisher: ACS Publications

All outputs in CentAUR are protected by Intellectual Property Rights law, including copyright law. Copyright and IPR is retained by the creators or other copyright holders. Terms and conditions for use of this material are defined in the End User Agreement.

www.reading.ac.uk/centaur 
Central Archive at the University of Reading

Reading's research outputs online 


\section{Skutterudite Thermoelectric Modules with High}

\section{Volume-Power-Density: \\ Scalability \\ and}

\section{Reproducibility}

Jesús Prado-Gonjal, ${ }^{\ddagger}$ Matthew Phillips,${ }^{\S}$ Paz Vaqueiro, ${ }^{\ddagger}$ Gao Min, ${ }^{\S *}$ Anthony V. Powell ${ }^{*}$

$\ddagger$ Department of Chemistry, University of Reading, RG6 6AD, Reading, UK

${ }^{\S}$ Cardiff School of Engineering, Cardiff University, The Parade, CF24 3AA, Cardiff, UK

KEYWORDS: Thermoelectric module, skutterudite, thermoelectric properties, high volumepower-density, waste heat recovery, energy harvesting, ball milling

\section{ABSTRACT}

The construction and evaluation of wholly-skutterudite thermoelectric modules with a high volume-power-density is described. Such modules afford the maximum power output for the minimum use of material. Synthesis of the component n-type unfilled skutterudite $\mathrm{CoSb}_{2.75} \mathrm{Sn}_{0.05} \mathrm{Te}_{0.20}$ and p-type filled skutterudite $\mathrm{Ce}_{0.5} \mathrm{Yb}_{0.5} \mathrm{Fe}_{3.25} \mathrm{Co}_{0.75} \mathrm{Sb}_{12}$, was achieved using a scalable ball-milling route that provides sufficient material for the construction and assessment of performance of 12 modules. Impedance spectroscopy at room temperature is shown to provide a rapid means of evaluating the quality of module fabrication. The results show a high degree of reproducibility in module performance across the 12 modules, with an average internal resistance 
of 102(4) $\mathrm{m} \Omega$. Electrical measurements on the component $n$ - and p-type materials reveal power factors $\left(S^{2} \sigma\right)$ of 1.92 and $1.33 \mathrm{~mW} \mathrm{~m}^{-1} \mathrm{~K}^{-2}$, respectively, at room temperature and maximum figures of merit of $Z T=1.13$ (n-type) and $Z T=0.91$ (p-type) at $673 \mathrm{~K}$ and $823 \mathrm{~K}$, respectively. The figure of merit of the module at room temperature $(Z T=0.12)$ is reduced by $c a .39 \%$ from the average of the $n$ - and p-type component materials at the same temperature, as a result of thermal- and electrical-contact resistance losses associated with the architecture of the module. I$\mathrm{V}$ curves for the module determined for $\Delta \mathrm{T}$ in the range $50-450 \mathrm{~K}$ show an almost linear dependence of the open-circuit voltage on $\Delta \mathrm{T}$ and allow calculation of the power output, which reaches a maximum value of $1.8 \mathrm{~W}\left(0.9 \mathrm{~W} \mathrm{~cm}^{-2}\right)$ at $\Delta \mathrm{T}=448 \mathrm{~K}$.

\section{Introduction}

Thermoelectric (TE) modules, composed of pairs of n-type and p-type semiconductors, may be used for direct thermal to electrical energy conversion. TE technology is particularly attractive for waste-heat energy harvesting in automobiles. ${ }^{1-4}$ For a gasoline-engined vehicle, $c a .30 \%$ of the primary gasoline energy is lost as waste heat in the exhaust gas, with a similar proportion lost in the engine-cooling system. ${ }^{5}$ Using a thermoelectric generator (TEG), a proportion of this waste heat can be converted into electrical power. Furthermore, by increasing the efficiency of fossil fuel usage in combustion engines, TE technology has the potential to make an important contribution to reducing $\mathrm{CO}_{2}$ and greenhouse gas emissions. ${ }^{6,78}$ In 1998, Nissan fabricated the first TEG for automobiles based on $\mathrm{Si}-\mathrm{Ge}$ elements. ${ }^{9-10}$ and subsequent generators have been constructed using modules fabricated with $\mathrm{Bi}_{2} \mathrm{Te}_{3}{ }^{11}$ as well as half-Heusler ${ }^{12}$ and skutterudite based materials. ${ }^{13-14}$ However, the most commonly-available commercial power-generating TE 
modules are still currently based on $\mathrm{Bi}_{2} \mathrm{Te}_{3}$ alloys. These modules suffer from the limitation that there is a fall-off in performance of the $\mathrm{Bi}_{2} \mathrm{Te}_{3}$-based materials at higher temperatures. ${ }^{15-16}$ Automotive applications therefore require the development of new modules containing materials that exhibit high performance at the higher temperatures appropriate to vehicle exhaust-gas streams.

High TE performance requires materials that exhibit the combination of a low electrical resistivity $(\rho)$ and thermal conductivity $(\kappa)$ concomitantly with a high Seebeck coefficient $(S)$. This unusual combination of properties maximizes the figure of merit $Z T$ (Eq. 1).

$$
Z T=\frac{S^{2}}{\rho \kappa} T
$$

The power factor $\left(\mathrm{PF}=S^{2} / \rho\right)$ may be optimized by controlling the carrier concentration through doping or chemical substitution in the materials. High mobility carriers are desirable and semiconductors best fulfil these requirements, having typical carrier concentrations of $10^{19}$ to $10^{21}$ carriers $\mathrm{cm}^{-3}{ }^{3,17-18}$ The efficiency of TE energy recovery $(\eta)$ is related directly to this figure of merit by:

$$
\eta=\left(\frac{\Delta T}{T_{h}}\right) \frac{\sqrt{Z \bar{T}+1}-1}{\sqrt{Z \bar{T}+1}+T_{C} / T_{h}}
$$

where $\Delta T$ is the difference in temperature between the hot $\left(T_{\mathrm{h}}\right)$ and cold $\left(T_{\mathrm{C}}\right)$ sides of the TEG and $Z \bar{T}$ the average figure of merit over the temperature range $\Delta T$. Maximising the efficiency requires both a large $\Delta T$ and also a large average $Z T$. 
Skutterudite-based materials are promising candidates from which to fabricate modules for hightemperature applications. ${ }^{13,19-21}$ Binary skutterudites may be formulated as $\mathrm{MX}_{3}$, where $\mathrm{M}$ is a transition metal and $\mathrm{X}$ is an element from Group 15. The skutterudite structure consists of a framework of corner-sharing $\mathrm{MX}_{6}$ octahedra, in which there are large cages able to accommodate filler species, such as rare-earth cations (Figure 1). The fillers act as Einstein oscillators, exhibiting localised low-energy vibrational modes (often termed "rattling" vibrations), that can dramatically reduce the thermal conductivity $(\kappa)$ by scattering phonons, thereby reducing the lattice contribution to the thermal conductivity $\left(\kappa_{\mathrm{L}}\right)$. It has been demonstrated that double filling, ${ }^{22-24}$ as in p-type $\mathrm{Ce}_{0.5} \mathrm{Yb}_{0.5} \mathrm{Fe}_{3.25} \mathrm{Co}_{0.75} \mathrm{Sb}_{12}$ for example, increases the spectral range over which phonon scattering occurs, owing to the different resonance frequencies of the $\mathrm{Ce}$ and $\mathrm{Yb}$ fillers. This effects further reductions to the lattice thermal conductivity thereby improving the TE performance. ${ }^{25}$ Remarkably, the presence of $\mathrm{Sn}$ in the unfilled n-type skutterudite $\mathrm{CoSb}_{2.75} \mathrm{Sn}_{0.05} \mathrm{Te}_{0.20}$ also leads to enhancements in $\mathrm{ZT}^{26}$

The best-performing skutterudites exhibit an average $Z T=0.5$, which at $\Delta T=500 \mathrm{~K}$, corresponds to a calculated (Eq. 2) efficiency of $c a .8 .8 \%$. In practice, electrical and thermal contact losses associated with the construction of the module reduce this to $c a .7 \% .^{3,21}$

Here, we describe the construction and evaluation of high-temperature TE modules containing filled and unfilled skutterudites. $\mathrm{CoSb}_{2.75} \mathrm{Sn}_{0.05} \mathrm{Te}_{0.20}$ (n-type) and $\mathrm{Ce}_{0.5} \mathrm{Yb}_{0.5} \mathrm{Fe}_{3 \cdot 25} \mathrm{Co}_{0.75} \mathrm{Sb}_{12}$ (ptype) were synthesised by mechanochemical alloying. This affords a method that is scalable to production of large quantities of material: an essential feature for the large-scale implementation of TE technology in high-volume sectors, such as automotive. In addition to structural characterization and TE property measurements, the thermal compatibility and stability in air of the n- and p-type materials are assessed. The methodology for module fabrication and rapid 
screening of module quality, together with evaluation of TE performance at high temperatures $\left(T_{\mathrm{h}} \leq 746 \mathrm{~K}\right)$ is described and discussed. The results demonstrate that modules are stable up to $\Delta T=300 \mathrm{~K}\left(T_{\mathrm{h}}=575 \mathrm{~K}\right)$ and can be operated at higher temperatures, up to $\Delta T=400 \mathrm{~K}$ ( $T_{\text {hotside }}=675$ $\mathrm{K})$, for short periods with no noticeable degradation in performance.

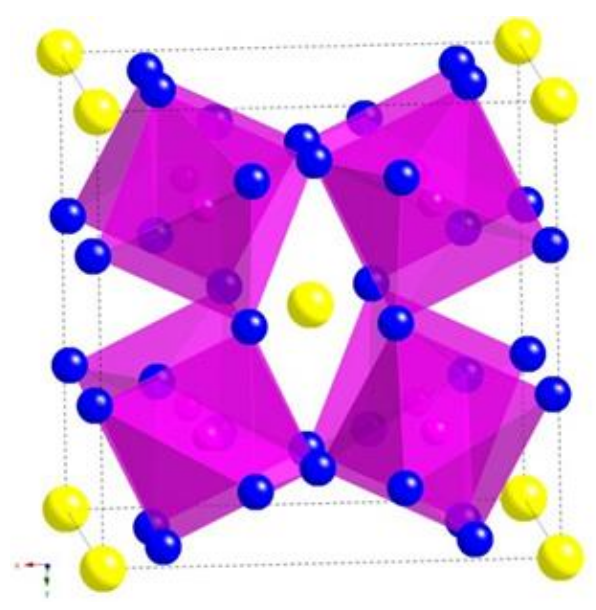

Figure 1. Crystal structure of a filled skutterudite. $\mathrm{MX}_{6}$ octahedra are shown in pink, with the $\mathrm{X}$ atoms represented by blue spheres and the filler atoms as yellow spheres.

\section{Experimental Section}

\section{Material preparation}

$\mathrm{CoSb}_{2.75} \mathrm{Sn}_{0.05} \mathrm{Te}_{0.20}$ (n-type material) and $\mathrm{Ce}_{0.5} \mathrm{Yb}_{0.5} \mathrm{Fe}_{3.25} \mathrm{Co}_{0.75} \mathrm{Sb}_{12}$ (p-type material) were prepared from mixtures of the elements Co (Alfa Aesar, 99.8\% powder), Sb (Alfa Aesar, 99.5\% powder), Sn (Aldrich, 99.9+ \% powder), Te (Aldrich, $99.99 \%$, granular), Ce (Alfa Aesar, 99.8\% ingot), $\mathrm{Yb}$ (Alfa Aesar, 99.9\% ingot) and Fe (Aldrich, 99.9+ \% powder) of appropriate stoichiometry. The mixtures were loaded into a $250 \mathrm{ml} \mathrm{ZrO} 2$ grinding vessel together with 13 $\mathrm{ZrO}_{2}$ balls (20 mm diameter). To minimise oxidation, the vessel was loaded inside an Argonfilled glove-box and sealed with a gas-tight lid. In the case of $\mathrm{Ce}_{0.5} \mathrm{Yb}_{0.5} \mathrm{Fe}_{3.25} \mathrm{Co}_{0.75} \mathrm{Sb}_{12}$, grinding 
was carried out at $400 \mathrm{rpm}$ for $10 \mathrm{~h}$ using a Fritsch P6 Planetary Ball Mill. For $\mathrm{CoSb}_{2.75} \mathrm{Sn}_{0.05} \mathrm{Te}_{0.20}$, the same conditions were used, although the milling was performed using a Retsch Planetary Ball Mill PM100. This approach enables batches of $>60 \mathrm{~g}$ of skutterudite powder to be prepared in the laboratory.

The ball-milled powders were loaded into a graphite die in an argon-filled glove box and consolidated by hot-pressing at $90 \mathrm{MPa}$ and $873 \mathrm{~K}\left(\mathrm{CoSb}_{2.75} \mathrm{Sn}_{0.05} \mathrm{Te}_{0.20}\right)$ or $823 \mathrm{~K}$ $\left(\mathrm{Ce}_{0.5} \mathrm{Yb}_{0.5} \mathrm{Fe}_{3.25} \mathrm{Co}_{0.75} \mathrm{Sb}_{12}\right)$ for 30 minutes. The consolidated pellets, used for the construction of the modules, are of $12.7 \mathrm{~mm}$ diameter $c a .2 .2 \mathrm{~mm}$ thickness. The densities of the consolidated pellets were determined using an ADAM PW184 Archimedes balance. Densities are between $7.47-7.59 \mathrm{~g} \mathrm{~cm}^{-3}$ for $\mathrm{CoSb}_{2.75} \mathrm{Sn}_{0.05} \mathrm{Te}_{0.20}$, corresponding to $98.3-99.8 \%$ of the theoretical density and $7.7-7.9 \mathrm{~g} \mathrm{~cm}^{-3}(96.3-98.8 \%)$ for $\mathrm{Ce}_{0.5} \mathrm{Yb}_{0.5} \mathrm{Fe}_{3.25} \mathrm{Co}_{0.75} \mathrm{Sb}_{12}$.

\section{Material characterization}

Temperature-dependent $(300$ - $673 \mathrm{~K})$ powder X-ray diffraction data were collected using a Bruker D8 Advance Powder X-ray diffractometer, operating with Ge-monochromated Cu Kal radiation $(\lambda=1.54046 \AA)$ and fitted with a LynxEye detector. A fragment of each of the skutterudite pellets was ground and the powder was placed inside a glass capillary with a diameter of $0.5 \mathrm{~mm}$. Data were measured over the angular range $10 \leq 2 \theta /{ }^{\circ} \leq 100$ for 4 hours with rotation of the capillary during the data collection. Unit-cell parameters were determined in FullProf, using the Le Bail method. ${ }^{27}$ A pseudo-Voigt function was used to describe the peak shape, while linear interpolation was used to fit the background.

The chemical composition of the samples was determined by ICP-MS, using an Agilent 7700 instrument, after microwave digestion of $50 \mathrm{mg}$ of finely ground sample in aqua regia. The 
thermal stability in air was investigated using a TA-Q600SDT TGA instrument. Measurements were conducted on a fragment $(c a .50 \mathrm{mg})$ of a pellet. The samples were heated from room temperature to $873 \mathrm{~K}$, at a ramp rate of $5 \mathrm{~K} \mathrm{~min}^{-1}$. Scanning Electron Microscopy (SEM) was performed on consolidated pellets using a FEI Quanta FEG 600 Environmental Scanning Electron Microscope.

The temperature dependence of electrical resistivity $(\rho)$ and Seebeck coefficient $(S)$ were measured over the temperature range $303 \leq T / \mathrm{K} \leq 823$ using a Linseis LSR-3 instrument. Measurements were conducted under a partial pressure of He. A temperature gradient of $50 \mathrm{~K}$ was used to determine the Seebeck coefficient and 4-probe resistance measurements were carried out using a current of $100 \mathrm{~mA}$.

The thermal diffusivity $(\alpha)$ and heat capacity $\left(C_{p}\right)$ of the samples were determined using a Netzsch LFA 447 NanoFlash. Data were collected over the temperature range $300 \leq T / \mathrm{K} \leq 573$ in $25 \mathrm{~K}$ steps. Measurements at higher temperatures $(573 \leq T / \mathrm{K} \leq 823 \mathrm{~K}$ in $50 \mathrm{~K}$ steps $)$ were carried out using an Anter Flashline 3000 instrument. The surface of the pellets was coated with graphite. The thermal conductivity $(\kappa)$ is given by $\kappa=\alpha \mathrm{C}_{\mathrm{p}} d$, where $d$ is the sample density. Pyroceram $^{\mathrm{TM}} 9606$, was used as a reference to allow determination of the heat capacity of the skutterudites. The thermal diffusivity was calculated using Cowan's model. ${ }^{28}$ The electronic $\left(\kappa_{\mathrm{e}}\right)$ component of the thermal conductivity was estimated using the Wiedemann-Franz law using values of the Lorenz number determined from the expression. $\mathrm{L}=1.5+\exp [-|\mathrm{S}| / 116]$, where $\mathrm{L}$ is in $10^{-8} \mathrm{~W} \Omega \mathrm{K}^{-2}$ and $\mathrm{S}$ in $\mu \mathrm{V} \mathrm{K}^{-1}{ }^{29}$ The lattice contribution $\left(\kappa_{\mathrm{L}}\right)$ was obtained by subtraction.

\section{Module fabrication}


Modules consisting of an array of nine thermocouples were fabricated from $13 \mathrm{~mm}$ diameter pellets of the n-type and p-type skutterudites (Figure 2(a)). Pellets were polished to a uniform thickness of approximately $2.2 \mathrm{~mm}$. Layers of palladium and nickel layer were sequentially applied to the top and bottom surfaces by electroplating in order to create a diffusion barrier. The total thickness of the barrier layer was determined to be $10 \mu \mathrm{m}$ by microscopy. The pellets were cut into thermoelements of approximate dimensions $1.7 \times 1.7 \times 2.2 \mathrm{~mm}$, using an Accutom-100 automated diamond cutting wheel. Two alumina ceramic plates $(16 \times 13 \times 0.63$ $\mathrm{mm}$ ) with bonded $2 \times 5 \times 0.35 \mathrm{~mm}$ copper strips (European Thermodynamics Ltd) were used to provide the thermal and electrical contacts, using the high temperature solder $\mathrm{Pb}_{93.5} \mathrm{Sn}_{5} \mathrm{Ag}_{1.5}$ (melting point $c a .569 \mathrm{~K}$ ). All the components (thermoelements, alumina plates, and solder pieces) were assembled using a homemade stainless-steel holder. To ensure a good bond, flux paste was spread between both the thermoelement/solder and solder/copper strip interfaces. The module assembly was then placed in a quartz tube, under an argon atmosphere, and the tube inserted into a tube furnace. The module assembly was heated to $623 \mathrm{~K}$ in order to melt the soldered joints. The holder was removed and the module assembly cooled under an argon atmosphere. Electrical contact was provided by soldering two wires to the cold side of the module. 
(a)

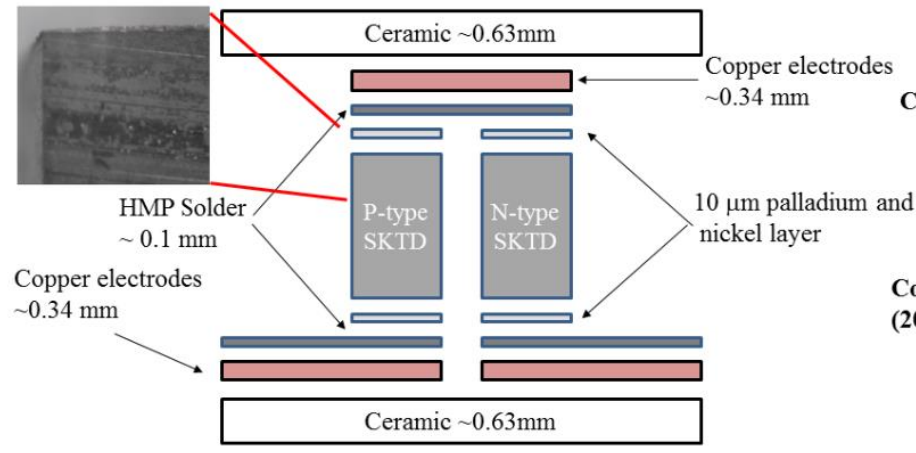

(b)

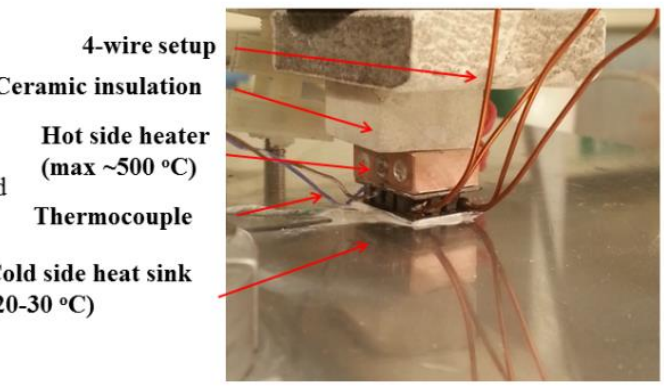

Figure 2. (a) Schematic diagram of the construction of a thermoelectric couple illustrating the different components. (b) Experimental set-up for module power measurements.

Skutterudite modules have an optimum operating window of around $573-773 \mathrm{~K}$. Braze materials with a melting temperature $50-100 \mathrm{~K}$ higher are required to join the thermoelements to ensure stable operation. Although silver braze materials with melting temperatures above $873 \mathrm{~K}$ are potentially suitable, when tested at these brazing temperatures, the silver braze tended not to wet fully the surface of the n-type material, preventing a strong mechanical bond from being achieved. Although the cause of the poor wetting is not known, it may be related to the brazing occurring at temperatures higher than the consolidation temperature of the skutterudite pellet. A discolouration of the n-type elements is observed in the region of the joining area after brazing with a silver-based braze. This may indicate chemical reaction at the surface of the thermoelement that disrupts the joining process. For this reason, lead-based solders were used to fabricate the modules reported here as they enable fabrication to be achieved below the temperature at which the thermoelements are consolidated. Although this imposes an upper limit on the temperature of operation of the module, the results reported below indicate that the modules produce high volume-power-densities even at $\Delta \mathrm{T}=448 \mathrm{~K}$ and that efforts to understand the nature of the interaction between high-temperature silver brazes and the skutterudite 
materials at elevated temperatures, which would allow the use of high-temperature brazes, would prove fruitful in achieving even higher power densities.

\section{Module characterization}

Rapid screening to ensure correct assembly of the twelve fabricated modules was carried out using impedance spectroscopy. Measurements were performed using an Autolab PGSTAT302N potentiostat with the results analysed through ZPlot software. The electrical impedance of the TE module was measured over the $\mathrm{mHz}$ to $\mathrm{kHz}$ range at room temperature. The data are described by an expression for an equivalent circuit, the variables of which are refinable parameters that allow determination of the internal resistance and the TE properties. The data provide an estimated ZT value (full details of the procedure have been published elsewhere ${ }^{30-32}$ ), sufficient to confirm the module quality.

Module power measurements (Figure 2(b)) were carried out using a custom-made moduletesting chamber evacuated through a turbo-molecular pump. The module was mounted to the base of the chamber using heat transfer paste, with the water-cooled base acting as the cold sink for the module. The heat source comprises a copper block with inserts for cartridge heaters that provide up to $100 \mathrm{~W}$. The heater block and module are approximately the same size, in order to minimise thermal losses. A clamping plate holds the heater block against the module. $20 \mathrm{~mm}$ of thermal insulation is used to minimise thermal losses between the heater block and the springloaded clamping plate. To ensure good thermal contact between the heater block and the module, graphite sheet was used to minimise any voids at the interfaces. Thermocouples (TCs) are located in indentations in the heater block and cold sink to enable measurement of the temperature at the interfaces of the heat transfer layers. 
The module output-power and heater input-power were measured using separate voltage and current leads, in order to nullify resistances other than those due to the module and connection wires. The system was evacuated, typically to $5 \times 10^{-6} \mathrm{mbar}$, and once a stable pressure was achieved, a B\&K Precision 9183 power supply was used to raise the heater to a set temperature and maintain a constant heat flow through the module. When a stable set temperature was achieved, fast I-V trace curves were measured from open-circuit to short-circuit conditions, using a Keithley 2460 source-measurement unit. Measurements were carried out with a scan rate of 5 $\mathrm{V} \mathrm{s}^{-1}$, in order to ensure a constant temperature throughout the data collection. The output voltage and module internal resistance are calculated from the curve, together with the power output of the module at that temperature.

\section{Results and Discussion}

\section{Structural and compositional characterization}

Powder X-ray diffraction data for the as-prepared ball-milled materials and the consolidated ballmilled materials are presented in Figure 3. It is evident that the formation mechanisms of $\mathrm{CoSb}_{2.75} \mathrm{Sn}_{0.05} \mathrm{Te}_{0.20}$ and $\mathrm{Ce}_{0.5} \mathrm{Yb}_{0.5} \mathrm{Fe}_{3.25} \mathrm{Co}_{0.7} \mathrm{Sb}_{12}$ differ. In the case of $\mathrm{Ce}_{0.5} \mathrm{Yb}_{0.5} \mathrm{Fe}_{3.25} \mathrm{Co}_{0.75} \mathrm{Sb}_{12}$, the skutterudite phase is already present after ball milling, whereas for $\mathrm{CoSb}_{2.75} \mathrm{Sn}_{0.05} \mathrm{Te}_{0.20}$, ball milling simply reduces the particle size of the components, as evidenced by the significant broadening of the diffraction peaks; a hot-pressing process is necessary to complete the crystallization of the skutterudite phase. Our data indicate that the formation of $\mathrm{CoSb}_{2.75} \mathrm{Sn}_{0.05} \mathrm{Te}_{0.20}$ on hot-pressing occurs below $823 \mathrm{~K}$ (Figure $\mathrm{S} 1$, Supplementary Information), but hot pressing at $873 \mathrm{~K}$ is required to produce consolidated pellets with densities 
close to the theoretical value. SEM micrographs (Figure S2, Supplementary Information) of the consolidated materials show a dense and void-free microstructure.

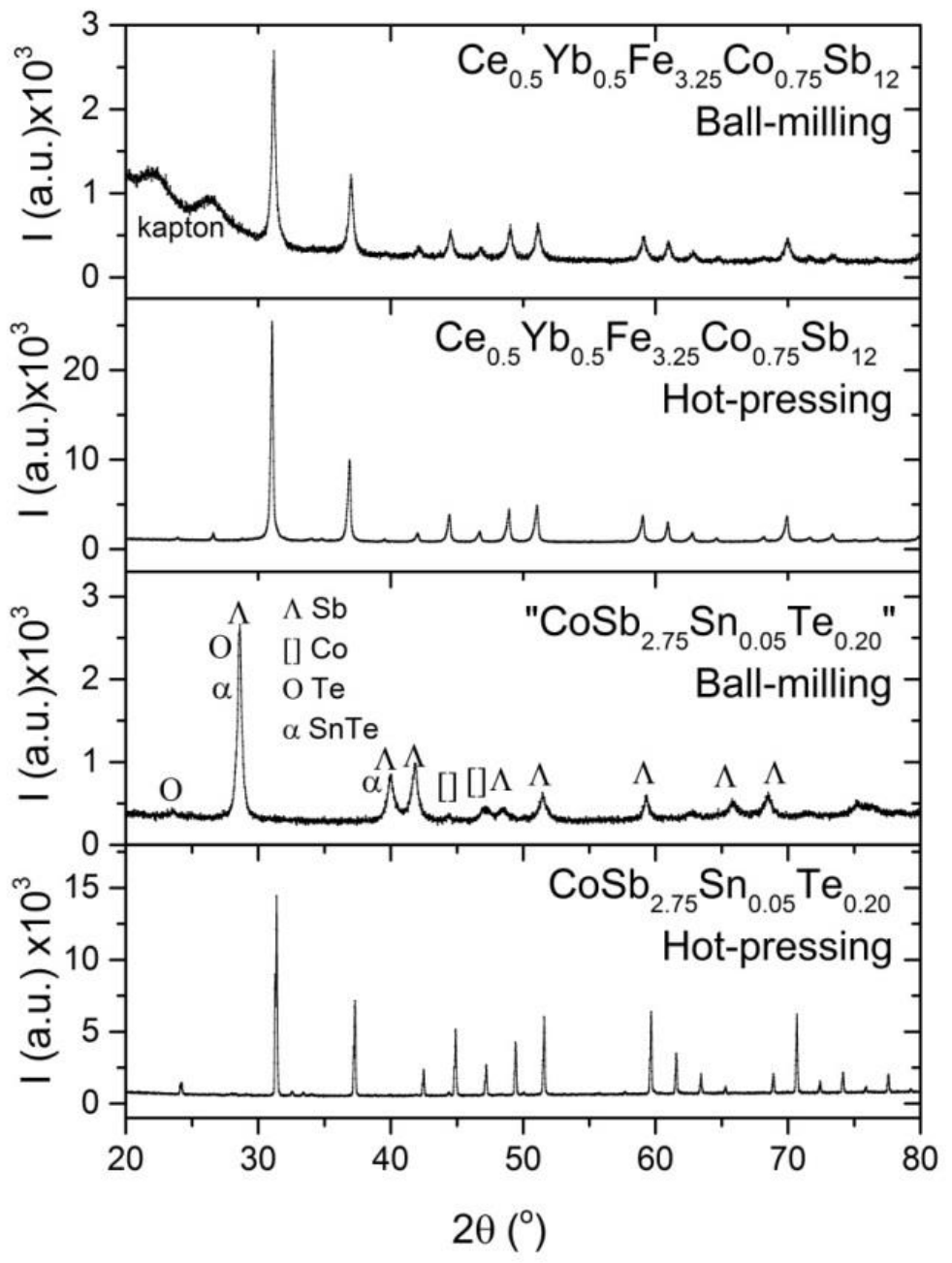

Figure 3. Powder $\mathrm{X}$ ray diffraction patterns of the as-prepared ball-milled materials and the same samples after consolidation by hot pressing.

All of the reflections in the powder diffraction patterns of the hot-pressed samples can be indexed using a cubic $(\operatorname{Im} \overline{3})$ unit cell. Room-temperature lattice parameters, obtained from Le Bail fitting, are $\mathrm{a}=9.0483(1) \AA$ and 9.12077(9) $\AA$ for $\mathrm{CoSb}_{2.75} \mathrm{Sn}_{0.05} \mathrm{Te}_{0.20}$ and $\mathrm{Ce}_{0.5} \mathrm{Yb}_{0.5} \mathrm{Fe}_{3.25} \mathrm{Co}_{0.7} \mathrm{Sb}_{12}$, respectively. 
The stoichiometry of the hot-pressed samples was confirmed by ICP - MS. This yields compositions of $\mathrm{Co}_{0.99} \mathrm{Sb}_{2.72} \mathrm{Sn}_{0.05} \mathrm{Te}_{0.20}$ and $\mathrm{Ce}_{0.51} \mathrm{Yb}_{0.47} \mathrm{Fe}_{3.13} \mathrm{Co}_{0.79} \mathrm{Sb}_{12.02}$, in good agreement with the nominal stoichiometries.

\section{Stability in air}

The thermal stability of the materials is of critical importance for devices intended to operate at elevated temperatures. The susceptibility of the materials to oxidation was investigated by thermogravimetric analysis (TGA). On heating consolidated materials in air, oxidation of $\mathrm{CoSb}_{2.75} \mathrm{Sn}_{0.05} \mathrm{Te}_{0.20}$ and $\mathrm{Ce}_{0.5} \mathrm{Yb}_{0.5} \mathrm{Fe}_{3.25} \mathrm{Co}_{0.7} \mathrm{Sb}_{12}$ begins above $773 \mathrm{~K}$ and $744 \mathrm{~K}$, respectively (Figure 4). The maximum operating temperature proposed for high-temperature TE devices used to recover the waste heat from vehicle exhaust systems is around $700-773 \mathrm{~K} .{ }^{33-34}$ The stability in air of the consolidated materials established here indicates that the $\mathrm{n}$ - and p-type skutterudites prepared are suitable for high-temperature TE applications.

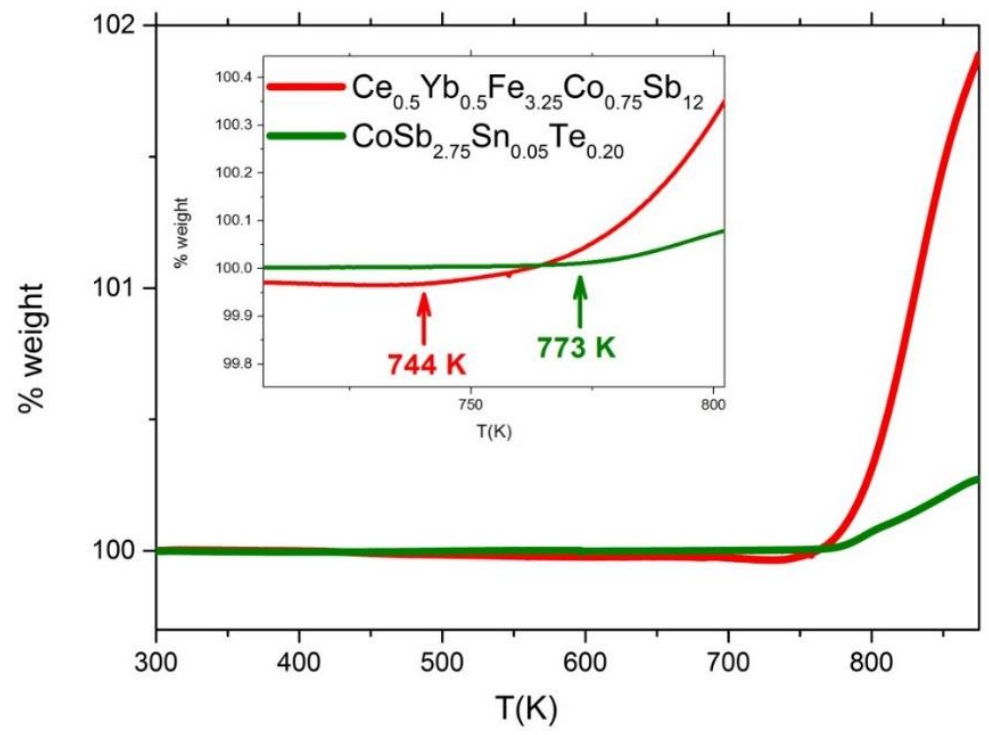

Figure 4. Thermogravimetric analysis (TGA) for $\operatorname{CoSb}_{2.75} \mathrm{Sn}_{0.05} \mathrm{Te}_{0.20}$ and $\mathrm{Ce}_{0.5} \mathrm{Yb}_{0.5} \mathrm{Fe}_{3.25} \mathrm{Co}_{0.7} \mathrm{Sb}_{12}$ pellets. The inset shows an enlargement of the region of the TGA curve 
from 700 to $810 \mathrm{~K}$. An increase in weight, corresponding to the onset of oxidation, can be observed above $773 \mathrm{~K}$ for $\mathrm{CoSb}_{2.75} \mathrm{Sn}_{0.05} \mathrm{Te}_{0.20}$ and $744 \mathrm{~K}$ for $\mathrm{Ce}_{0.5} \mathrm{Yb}_{0.5} \mathrm{Fe}_{3.25} \mathrm{Co}_{0.7} \mathrm{Sb}_{12}$.

\section{Thermal expansion coefficient}

Long-term stability of a TE module requires mechanical stresses in the module at the high operating temperatures to be minimised, necessitating similar thermal expansion coefficients for the $\mathrm{n}$ - and p-type components. ${ }^{35}$ The thermal expansion coefficient $(\alpha)$ of a number of skutterudites have been determined; ${ }^{36-38}$ the review of Rogl et al..$^{39}$ providing data for around 50 different compositions. Thermal expansion coefficients for the materials presented here were determined using lattice parameters obtained from an X-ray thermodiffraction experiment (Figure 5 and Figure S3, Supplementary information).

The thermal expansion coefficient $(\alpha)$ is related to the lattice parameters of a cubic material at different temperatures are to by:

$$
\alpha=\frac{\left(a_{T 2}-a_{T 1}\right) / a_{T 1}}{\Delta T}
$$

where $a_{T 1}$ and $a_{T 2}$ are the lattice parameters at temperatures $T_{1}$ and $T_{2}$, and $\Delta T$ corresponds to the temperature difference, $\left(T_{2}-T_{1}\right)$. 


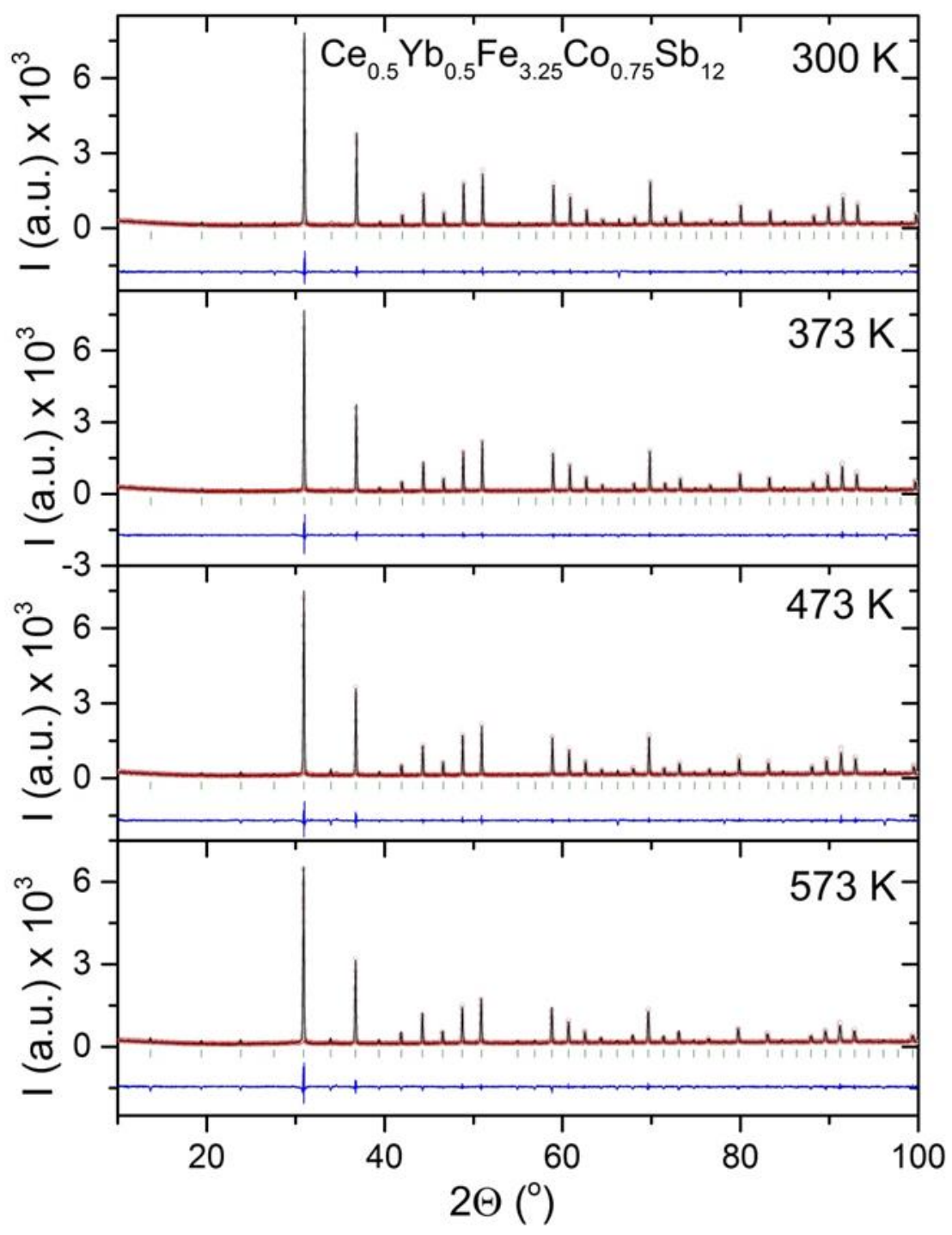

Figure 5. Final observed (red dotted line), calculated (black solid line) and difference (blue line) profiles for structure-independent Le Bail refinement using X-ray diffraction data for $\mathrm{Ce}_{0.5} \mathrm{Yb}_{0.5} \mathrm{Fe}_{3.25} \mathrm{Co}_{0.7} \mathrm{Sb}_{12}$ from room temperature to $573 \mathrm{~K}$. Green markers indicate the reflection position for the skutterudite phase. Thermodiffraction data for $\mathrm{CoSb}_{2.75} \mathrm{Sn}_{0.05} \mathrm{Te}_{0.20}$ are provided as supplementary information (Figure S3). 


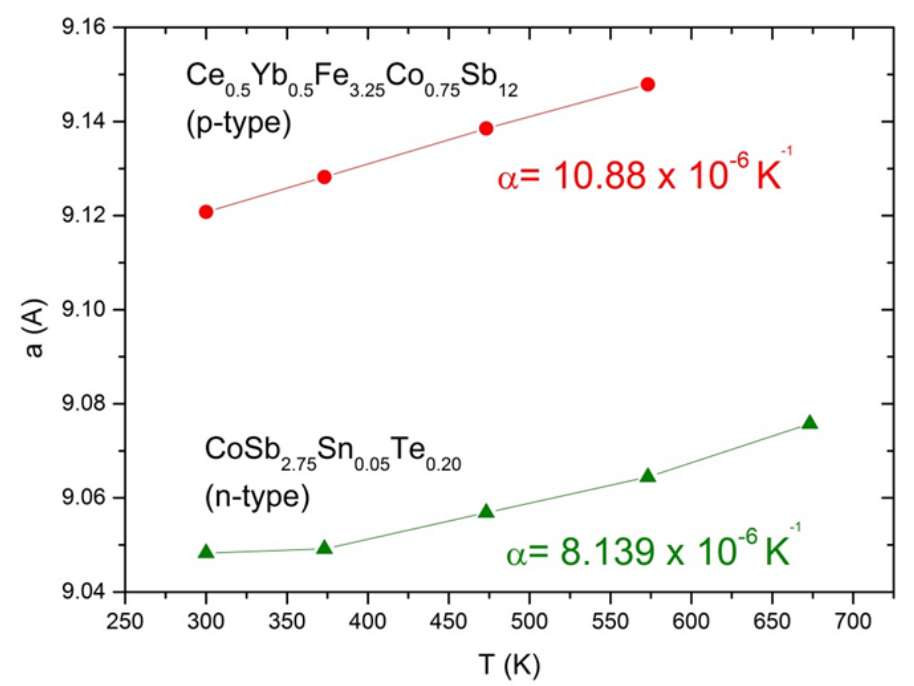

Figure 6. Temperature dependence of the lattice parameters obtained from Le Bail refinements using powder X-ray diffraction data.

The temperature dependence of the lattice parameters for both the $\mathrm{n}$ - and p-type materials (Figure 6) corresponds to a positive thermal expansion coefficient $(\alpha)$. The values of $\alpha$ calculated from Eq.3 for $\mathrm{CoSb}_{2.75} \mathrm{Sn}_{0.05} \mathrm{Te}_{0.20}$ and $\mathrm{Ce}_{0.5} \mathrm{Yb}_{0.5} \mathrm{Fe}_{3.25} \mathrm{Co}_{0.7} \mathrm{Sb}_{12}$ are $8.14 \times 10^{-6} \mathrm{~K}^{-1}$ and $10.88 \mathrm{x}$ $10^{-6} \mathrm{~K}^{-1}$, respectively. These values are comparable to those reported for other Sb-containing skutterudites, such as $\mathrm{Yb}_{\mathrm{x}} \mathrm{Co}_{4} \mathrm{Sb}_{12}$ (n-type, $\alpha=8.17 \mathrm{x} 10^{-6} \mathrm{~K}^{-1}$ ) or $\mathrm{Mm}_{0.7} \mathrm{Fe}_{3} \mathrm{CoSb}_{12}$ (p-type, $\alpha=$ $\left.11.33 \times 10^{-6} \mathrm{~K}^{-1}\right){ }^{39}$ The similarity of the thermal expansion coefficients for both thermoelements suggests that failure during thermal cycling due to thermal expansion mismatch is likely to be minimised.

\section{Thermoelectric properties of the materials}

The Seebeck coefficient $(S)$, electrical resistivity $(\rho)$ and power factor $(\mathrm{PF})$ for the two materials over the temperature range $300 \leq \mathrm{T} / \mathrm{K} \leq 823$ are presented in Figure 7 . Seebeck coefficient measurements confirm the $n$ - and p-type character of $\operatorname{CoSb}_{2.75} \operatorname{Sn}_{0.05} \mathrm{Te}_{0.20}$ and 
$\mathrm{Ce}_{0.5} \mathrm{Yb}_{0.5} \mathrm{Fe}_{3.25} \mathrm{Co}_{0.7} \mathrm{Sb}_{12}$ respectively. For both materials, the absolute value of the Seebeck coefficient increases with temperature, reaching maximum values of $-232 \mu \mathrm{V} \mathrm{K}^{-1}$ at $702 \mathrm{~K}$ and $156 \mu \mathrm{V} \mathrm{K}^{-1}$ at $813 \mathrm{~K}$, for the $\mathrm{n}$ - and p-type phases respectively.

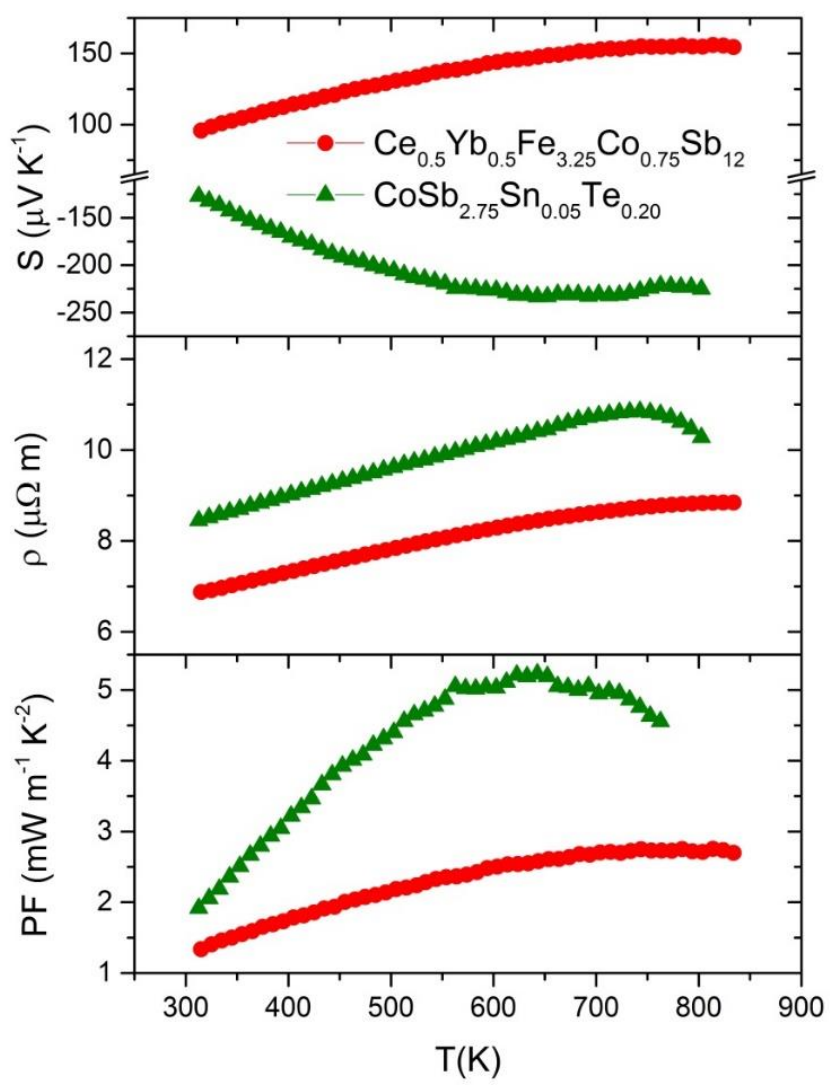

Figure 7. Temperature dependence of the Seebeck coefficient (S), electrical resistivity $(\rho)$ and power factor $\left(\mathrm{PF}=\mathrm{S}^{2} / \rho\right)$ of $\mathrm{CoSb}_{2.75} \mathrm{Sn}_{0.05} \mathrm{Te}_{0.20}$ (green triangles) and $\mathrm{Ce}_{0.5} \mathrm{Yb}_{0.5} \mathrm{Fe}_{3.25} \mathrm{Co}_{0.7} \mathrm{Sb}_{12}$ (red circles).

The electrical resistivity of the samples (Figure 7) increases slightly with increasing temperature; the behaviour expected for a metal. Although the resistivity of $\mathrm{CoSb}_{2.75} \mathrm{Sn}_{0.05} \mathrm{Te}_{0.20}$ at $300 \mathrm{~K}(\rho \approx$ $8.45 \mu \Omega \mathrm{m})$ is $c a .22 \%$ higher than that of $\mathrm{Ce}_{0.5} \mathrm{Yb}_{0.5} \mathrm{Fe}_{3.25} \mathrm{Co}_{0.7} \mathrm{Sb}_{12}(\rho \approx 6.88 \mu \Omega \mathrm{m})$, the large Seebeck coefficient of the former results in a relatively high power factor. The power factor 
reaches $5.22 \mathrm{~mW} \mathrm{~m}^{-1} \mathrm{~K}^{-2}$ at $640 \mathrm{~K}$ for $\mathrm{CoSb}_{2.75} \mathrm{Sn}_{0.05} \mathrm{Te}_{0.20}$. This compares with a value of 2.75 $\mathrm{mW} \mathrm{m}{ }^{-1} \mathrm{~K}^{-2}$ for $\mathrm{Ce}_{0.5} \mathrm{Yb}_{0.5} \mathrm{Fe}_{3.25} \mathrm{Co}_{0.7} \mathrm{Sb}_{12}$ at $813 \mathrm{~K}$.

The linear region of $S(\mathrm{~T})(300-600 \mathrm{~K})$ may be used to estimate the charge carrier concentration through the Mott formula (Eq. 4). ${ }^{40} 41$ This leads to carrier concentrations of $2.70 \times 10^{20} \mathrm{~cm}^{-3}$ for $\mathrm{CoSb}_{2.75} \mathrm{Sn}_{0.05} \mathrm{Te}_{0.20}$ and $1.02 \times 10^{21} \mathrm{~cm}^{-3}$ for $\mathrm{Ce}_{0.5} \mathrm{Yb}_{0.5} \mathrm{Fe}_{3.25} \mathrm{Co}_{0.7} \mathrm{Sb}_{12}$.

$$
S=\frac{\pi^{2} k_{B}^{2} 2 m_{e}}{e h^{2}\left(3 n \pi^{2}\right)^{2 / 3}} T
$$

The temperature dependence of the Seebeck coefficient also provides an estimate of the band gap $\left(E_{g}\right)$ through the Goldsmid and Sharp equation (Eq. 5), by considering the temperature $\left(T_{\max }\right)$ at which the maximum value of $|S|$ is observed $\left(S_{\max }\right) .{ }^{42}$ This approach leads to a band gap of $E_{g} \approx$ $0.33 \mathrm{eV}$ for $\mathrm{CoSb}_{2.75} \mathrm{Sn}_{0.05} \mathrm{Te}_{0.20}$, slightly higher than the value of $\mathrm{E}_{\mathrm{g}} \approx 0.25 \mathrm{eV}$ determined for $\mathrm{Ce}_{0.5} \mathrm{Yb}_{0.5} \mathrm{Fe}_{3.25} \mathrm{Co}_{0.7} \mathrm{Sb}_{12}$. Errors in band gaps determined in this way have been estimated to be up to $20 \%$ of the calculated value. ${ }^{42}$

$$
S_{\max }=\frac{E_{g}}{2 e T_{\max }}
$$

The total thermal conductivity of each material (Figure 8) is essentially invariant with temperature and significantly reduced from that of $\operatorname{CoSb}_{3}\left(\kappa \approx 8-10 \mathrm{~W} \mathrm{~m}^{-1} \mathrm{~K}^{-1}\right.$ at $\left.300 \mathrm{~K}\right){ }^{43-44}$ The slight discontinuity in the data at $573 \mathrm{~K}$ is due to a change in instrument for the measurement of thermal diffusivity in two different temperature ranges. The reduced thermal conductivity of these materials has different origins in the two materials. In the case of the unfilled skutterudite $\mathrm{CoSb}_{2.75} \mathrm{Sn}_{0.05} \mathrm{Te}_{0.20}$, incorporation of $\mathrm{Te}$ and $\mathrm{Sn}$ at the $\mathrm{Sb}$ site generates significant changes in the vibrational modes and, through point defect scattering, reduces the 
thermal conductivity. ${ }^{26}$ Nanostructure may also play a role. By contrast, the reduction in thermal conductivity of $\mathrm{Ce}_{0.5} \mathrm{Yb}_{0.5} \mathrm{Fe}_{3.25} \mathrm{Co}_{0.7} \mathrm{Sb}_{12}$ is due to the presence of two filler species with different rattling frequencies that produce phonon scattering over a broad range of the phonon spectrum. ${ }^{22,}$ 25

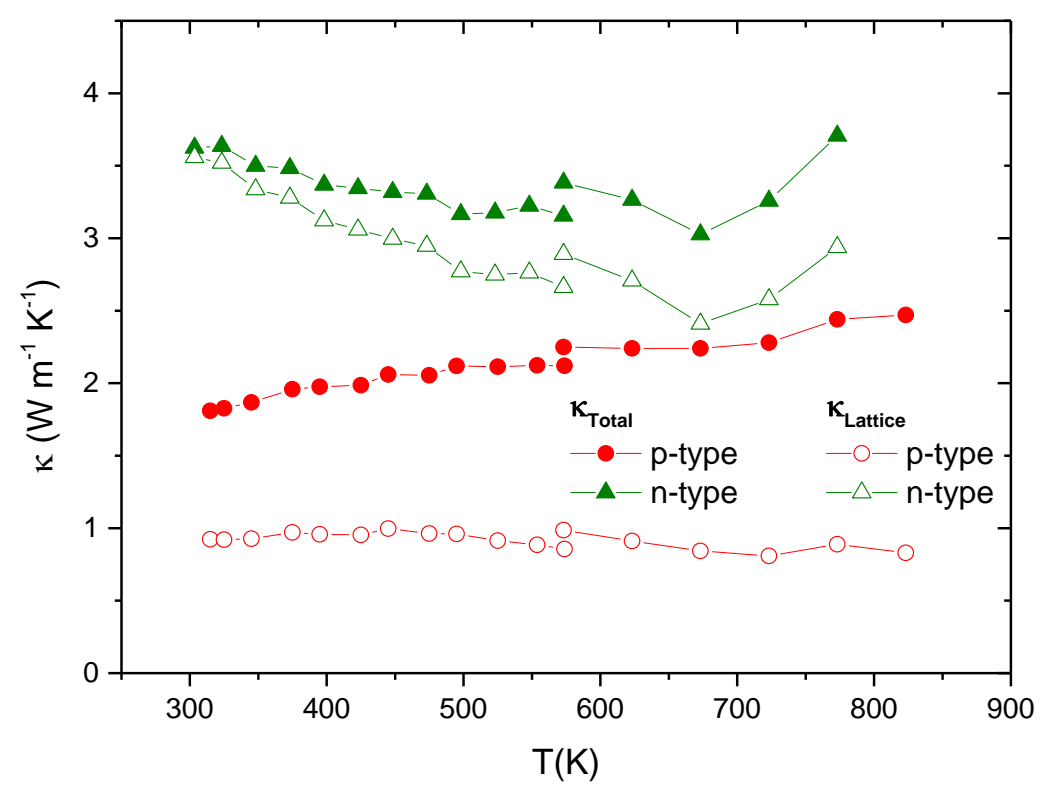

Figure 8. Total $\left(\kappa_{\text {Total }}\right)$ and lattice $\left(\kappa_{\text {Lattice}}\right)$ thermal conductivity of n-type $\mathrm{CoSb}_{2.75} \mathrm{Sn}_{0.05} \mathrm{Te}_{0.20}$ (green triangles) and p-type $\mathrm{Ce}_{0.5} \mathrm{Yb}_{0.5} \mathrm{Fe}_{3.25} \mathrm{Co}_{0.7} \mathrm{Sb}_{12}$ (red circles) as a function of temperature.

The maintenance of a high power factor, combined with a reduced thermal conductivity, produces a relatively high figure of merit, $Z T$. In both materials, $Z T$ increases with increasing temperature (Figure 9), reaching maximum values of 1.13 at $673 \mathrm{~K}$ and 0.91 at $823 \mathrm{~K}$ for $\mathrm{CoSb}_{2.75} \mathrm{Sn}_{0.05} \mathrm{Te}_{0.20}$ and $\mathrm{Ce}_{0.5} \mathrm{Yb}_{0.5} \mathrm{Fe}_{3.25} \mathrm{Co}_{0.7} \mathrm{Sb}_{12}$ respectively. It is notable that the figure of the merit of the latter is still rising at the highest temperature investigated. 


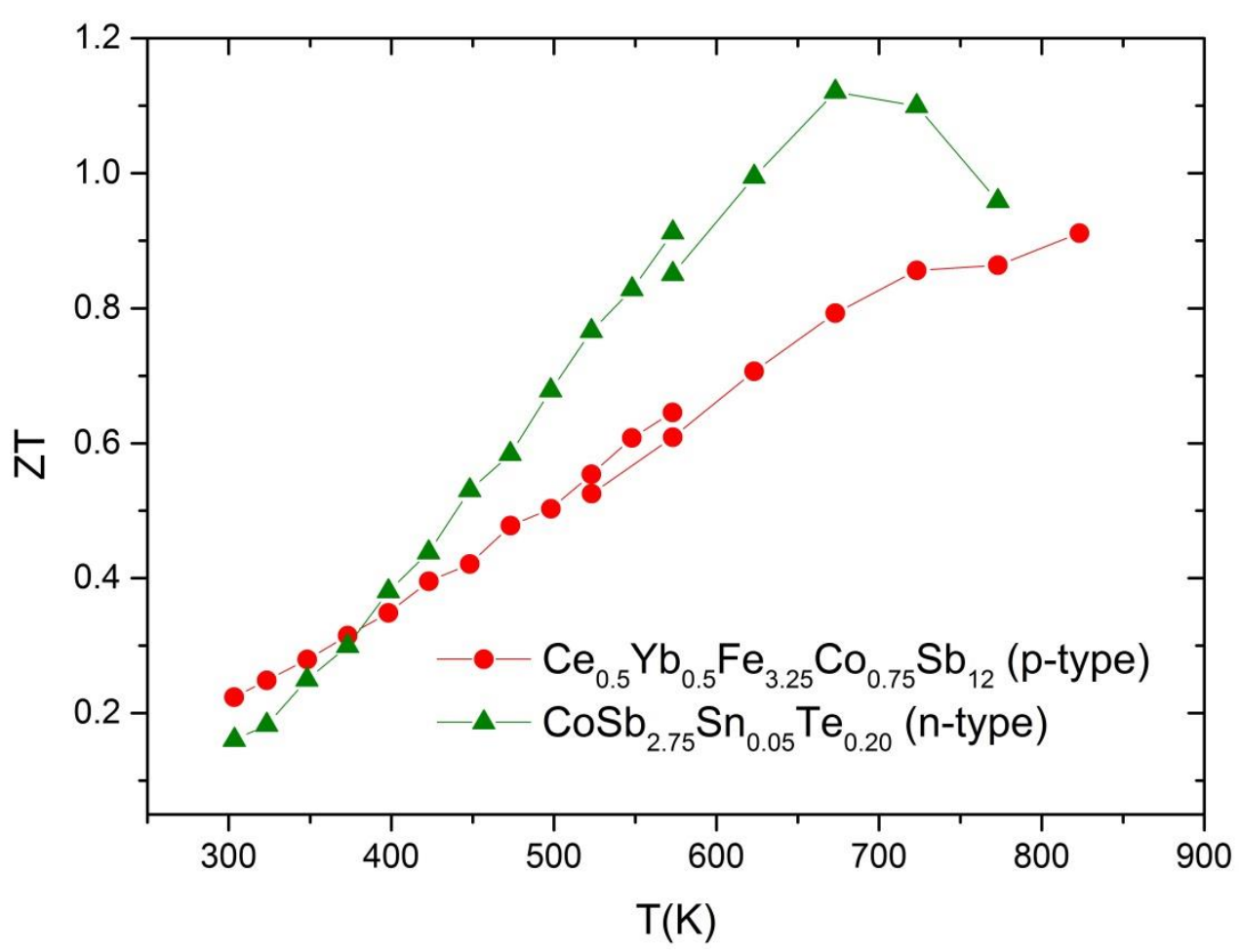

Figure 9. Temperature dependence of the figure of merit, ZT, of the n-type $\mathrm{CoSb}_{2.75} \mathrm{Sn}_{0.05} \mathrm{Te}_{0.20}$ (green triangles) and p-type $\mathrm{Ce}_{0.5} \mathrm{Yb}_{0.5} \mathrm{Fe}_{3.25} \mathrm{Co}_{0.7} \mathrm{Sb}_{12}$ (red circles) skutterudites.

\section{Module properties}

Twelve modules were fabricated and screened using impedance spectroscopy. The impedance plot (Figure 10) for a skutterudite module constructed from $\mathrm{CoSb}_{2.75} \mathrm{Sn}_{0.05} \mathrm{Te}_{0.20}$ and $\mathrm{Ce}_{0.5} \mathrm{Yb}_{0.5} \mathrm{Fe}_{3.25} \mathrm{Co}_{0.7} \mathrm{Sb}_{12}$ shows the typical 'Warburg like' shape, characteristic of a TE module. The total impedance $Z(j \omega)$ of the equivalent circuit, ${ }^{30-31}$ shown as an inset to Figure 10, is given by,

$$
Z(j \omega)=L+R+\frac{1}{Z_{W a}^{-1}+Z_{W_{C T}}^{-1}}
$$

where, $L$ is the inductance, $R$ is the internal resistance of the module, $W_{a}$ is the adiabatic Warburg impedance associated with the contacts and $W_{C T}$ is a constant-temperature Warburg impedance 
associated with the TE effect. The two Warburg impedances are described by equations (7) and $(8)$,

$$
\begin{aligned}
& Z_{W_{a}}(j \omega)=R_{C}\left(\frac{j \omega}{\omega_{C}}\right)^{-0.5} \operatorname{coth}\left\{\left(\frac{j \omega}{\omega_{C}}\right)^{0.5}\right\} \\
& Z_{W_{C T}}(j \omega)=R_{T E}\left(\frac{j \omega}{\omega_{T E}}\right)^{-0.5} \tanh \left\{\left(\frac{j \omega}{\omega_{T E}}\right)^{0.5}\right\}
\end{aligned}
$$

where $R_{C}$ and the $R_{T E}$ are the resistances associated with the contacts and TE responses respectively and $\omega_{C}$ and $\omega_{T E}$ are the characteristic angular frequencies. The four parameters, presented in Table 1, were obtained by fitting Eq. (6) to the experimental data of Figure 10.

Table 1. Parameters derived from the fit of Eq. (6) to the impedance data of a TE module, presented in Figure 10.

\begin{tabular}{|c|c|c|c|c|c|}
\hline $\mathbf{R} / \mathbf{m} \Omega$ & $\mathbf{R} / \%$ error & $\mathbf{R}_{\mathrm{TE}} / \mathbf{m} \Omega$ & $\mathbf{R}_{\mathrm{TE}} / \%$ error & $\boldsymbol{\omega}_{\mathrm{TE}} / \mathbf{r a d s}^{-1}$ & $\boldsymbol{\omega}_{\mathrm{TE}} / \%$ error \\
\hline 95 & 0.09 & 10.6 & 4.10 & 1.14 & 2.40 \\
\hline & & & & & \\
\hline $\mathbf{R}_{\mathbf{C}} / \mathbf{m} \Omega$ & $\mathbf{R}_{\mathbf{C}} / \%$ error & $\boldsymbol{\omega}_{\mathbf{C}} / \mathbf{r a d s}^{-\mathbf{1}}$ & $\boldsymbol{\omega}_{\mathbf{C}} / \mathbf{\%}$ error & $\mathbf{L} / \mathbf{n H}$ & $\mathbf{L} / \mathbf{\%}$ error \\
\hline 0.922 & 24.2 & 0.48 & 17.9 & 98 & 37.4 \\
\hline
\end{tabular}

It has been shown previously ${ }^{30-31}$ that $R_{T E}=2 N S^{2} T \ell / \kappa A$ where $S, T$ and $\kappa$ have their usual meanings, $N$ is the number of thermocouples in the module and $\ell$ and $A$ are the length and cross- 
sectional area of each thermoelement. It follows that an approximate $Z T$ value for the module may be obtained from the following relation;

$$
\frac{R_{T E}}{R}=2 N \frac{S^{2}}{\kappa} \frac{\ell}{A R} T=Z_{m o d} T
$$

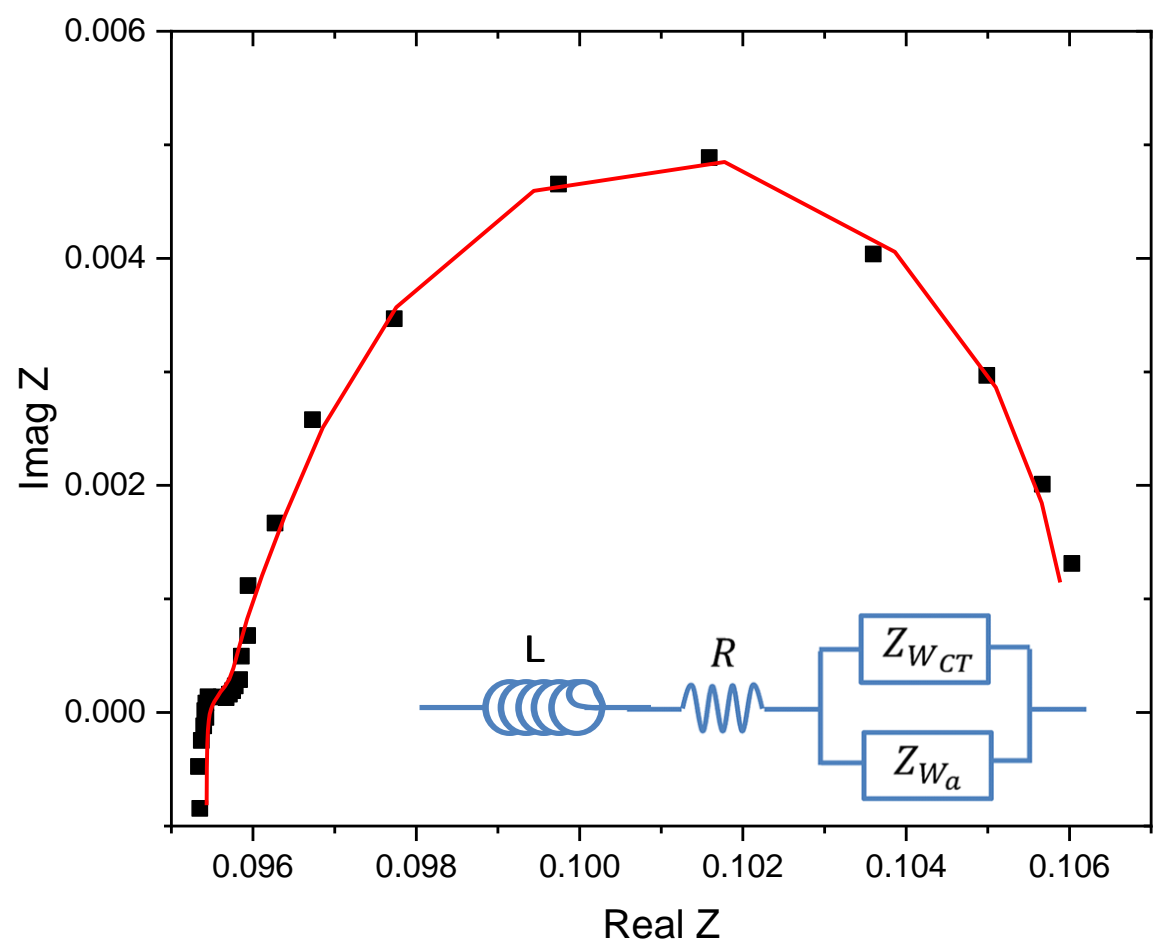

Figure 10. Impedance spectrum (black squares) for a skutterudite module from $5 \mathrm{mHz}$ to 10 kHz. The equivalent circuit for a TE module is shown as an inset and is used to generate the fit (red line) from which the module internal resistance and ZT at room temperature are calculated. The equivalent circuit consists of a resistor $R$ and an inductor $L$ in series with two impedances in parallel. $R$ is the internal resistance of the module, $W_{a}$ is the adiabatic Warburg impedance associated with the module contacts and $W_{C T}$ is the constant temperature Warburg impedance associated with the TE effect. ${ }^{30-31}$ 
Based on the fit to the data of Figure 10, the internal resistance of the module is determined as 95 $\mathrm{m} \Omega$. Using this value and the measured resistivity values of the n-type and p-type materials, the room temperature contact resistivity is estimated as $c a .10 \mu \Omega \mathrm{cm}^{2}$. The room-temperature figure of merit for the module has been estimated as $Z T=0.11$, using Eq. (9). This is reduced by $c a$. $39 \%$ from the average value of $Z T=0.18$ determined experimentally (Figure 9) for the $n$ - and $p$ type materials at the same temperature, owing to losses associated with the ceramic plates of the module. In order to verify that the difference in $Z T$ between that of the component n- and p-type materials and that of the module is due to contact losses and not experimental error, $Z T$ was also calculated using the efficiency determined from a constant heat flux I-V curve (Supporting Information). Using this technique, a value of $\mathrm{ZT} \sim 0.12$ is obtained, in excellent agreement with that determined above from resistivity data. The average internal resistance value for all the modules investigated is $101 \pm 1 \mathrm{~m} \Omega$ and their average figure-of-merit is ZT $=0.12 \pm 0.01$. The low standard deviation in these values is consistent with a high degree of reproducibility in module properties across the 12 modules fabricated. The module $Z \bar{T}$ value was verified using an efficiency calculation from a constant heat flow I-V curve (Supporting Information).

The module current-voltage (I-V) curves (Figure 11a) were obtained under constant temperature conditions for a series of temperature differences across the module, using a scan rate of $5 \mathrm{~V} \mathrm{~s}^{-1}$. There was no detectable drop in the hot-side temperature after the measurement was taken. There is an approximately linear relationship between open circuit voltage and $\Delta T$ up to $\Delta T=400 \mathrm{~K}$. Although a further increase in open-circuit voltage is observed at $\Delta T=448 \mathrm{~K}$, this is less than expected based on the linear dependence established at lower temperatures. At this temperature difference, the hot-side temperature is $c a .746 \mathrm{~K}$, well above the melting point of the solder (570 K) used to fabricate the module, suggesting that a failure at the skutterudite-electrode interface 
may be responsible for the loss of performance. Figure $11 \mathrm{~b}$ shows the output power and internal resistance for the module at each of the temperature differences. Although there are long term stability issues with working at temperatures in excess of the solder melting temperature, the results suggest measurements on short timescales are possible and can be used to benchmark the performance of future higher temperature brazes. The maximum power output achieved for the module is $c a .1 .85 \mathrm{~W}\left(0.9 \mathrm{Wcm}^{-2}\right)$ at $\Delta T=448 \mathrm{~K}$. This is much higher than the values previously reported by García-Cañadas et al. ${ }^{13}$ for a module constructed exclusively from single filled nand p-type skutterudites.
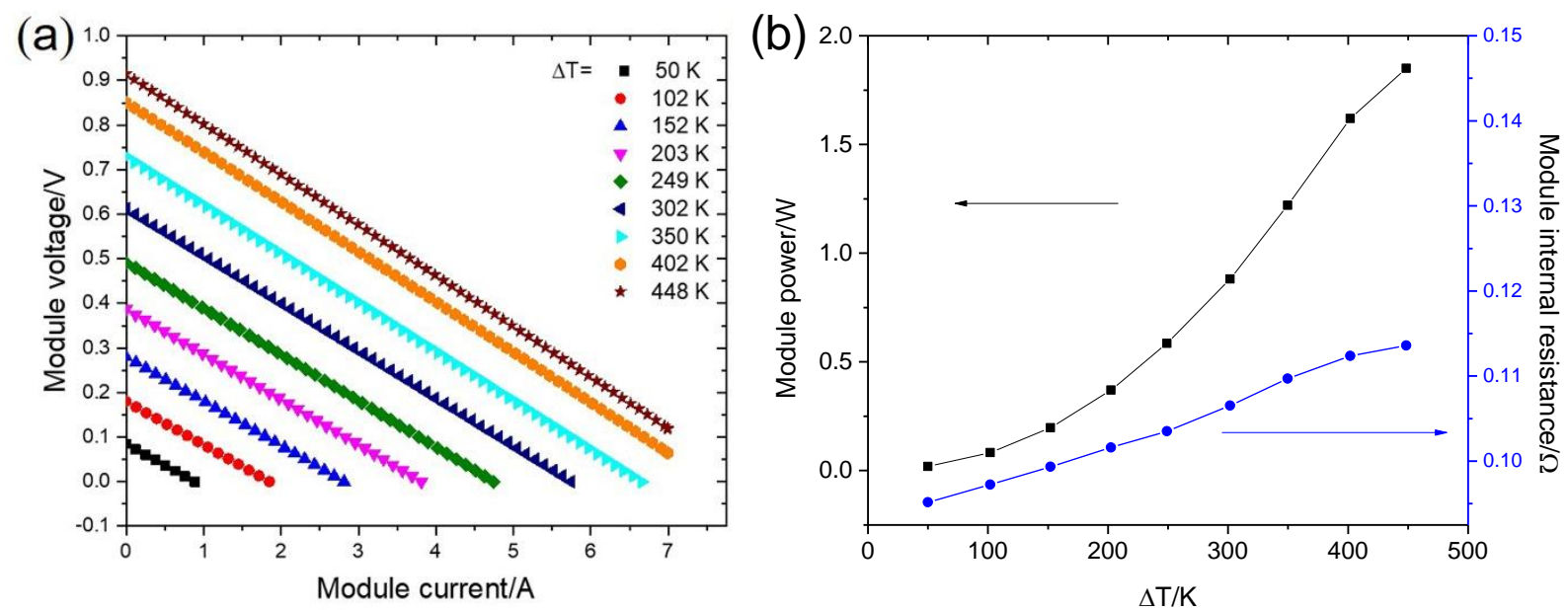

Figure 11. Module characteristics of a representative skutterudite module from $\Delta T=50 \mathrm{~K}$ to $\Delta T=448 \mathrm{~K}$. (a) I-V curves taken under constant temperature conditions with a voltage scan rate of $5 \mathrm{~V} \mathrm{~s}^{-1}$. (b) Module internal resistance (blue circles) and output power (black squares) for each of the applied temperature differences.

Further increases in output would be possible if a braze capable of operating at higher temperatures was used at the hot-side junctions of the module. The surface- and volume-power- 
densities as a function of temperature difference for the module described here, are compared with those of other skutterudite (Sktd) modules ${ }^{13,21}$ and modules constructed from materials such as $\mathrm{SiGe}^{45}, \mathrm{Bi}_{2} \mathrm{Te}_{3}{ }^{46}$ and Half-Heuslers $(\mathrm{HH})^{12}$ in Figure 12. Interestingly, the skutterudite module reported by Ochi et $a l .{ }^{20}$ has one of the lowest volume-power-densities but one of the highest surface-power-densities. This apparent contradiction may arise from efforts to improve the efficiency by increasing the leg length and cross-sectional area, thereby mitigating the effect of electrical contact losses. This comes at the expense of increased material usage and hence, a lower volume-power-density.
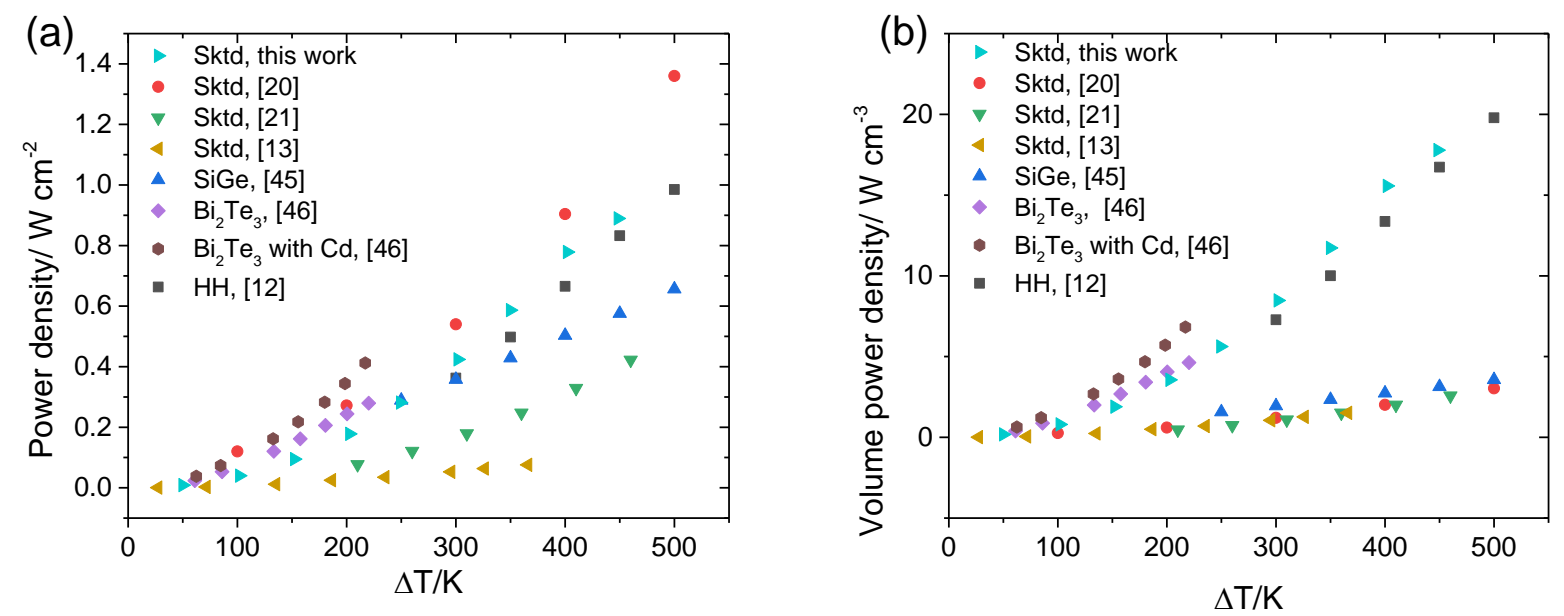

Figure 12. (a) Module surface-power-density and (b) volume-power-density as a function of temperature difference $\Delta \mathrm{T}$, for the module described in this work together with published data for high-temperature modules. The surface-power-density is the power output divided by the area in physical contact with the heat source. The volume-power-density is the output power divided by the total volume of the thermoelements of which the module is comprised. Sktd. and HH refer respectively to modules constructed from skutterudite and half-Heuslers. 
The module characterized in the present work has a high volume-power-density, affording more efficient use of material to generate a given power, a critical factor for large scale applications. More efficient use of material reduces the cost per watt for the module, but potentially limits the heat-power conversion efficiency, which we have estimated to be ca. 3 - 4\% under a temperature gradient of $362 \mathrm{~K}$ (Figure S5, Supplementary Information). Therefore, future work will seek to optimise the module geometry for applications such as automotive waste heat recovery, where a limited amount of heat flux is available. The performance of the module described here could be enhanced further by increasing the thermoelement length and cross-sectional area to increase the power output and efficiency. Furthermore, more robust barrier coatings are needed to allow brazing and extended operation at higher temperatures.

\section{Conclusions}

By adopting a holistic approach incorporating elements of materials design, considerations of scale-up of materials preparation, module construction and screening, we have succeeded in producing a batch of high-temperature skutterudite-based TE modules, with a high volumepower-density and reproducible TE characteristics. We describe a ball-milling process for the production of large $(>60 \mathrm{~g})$ quantities of $\mathrm{n}$ - and p-type skutterudites with $Z T \sim 1$ at elevated temperatures. We also show that impedance spectroscopy performed at room temperature provides an effective means of screening module performance in an efficient and effective manner. A maximum power output of $1.8 \mathrm{~W}$, equivalent to $0.9 \mathrm{~W} \mathrm{~cm}^{-2}$, is achieved at $\Delta \mathrm{T}=448$

$\mathrm{K}$. The upper limit of $\Delta T$ is determined by the melting point of the lead-based solder used for the electrical connections. Preliminary investigations with a high-temperature silver-based braze 
provide evidence for reaction between the braze and the thermoelement, that weakens the mechanical bonding. Future investigation will focus on understanding the nature of this interaction, and identifying brazes able to withstand higher temperatures, whilst providing an effective mechanical join and low electrical contact resistance. This would enable higher temperature operation of the module and increased output power.

\section{ASSOCIATED CONTENT}

Supporting Information. X-ray diffraction data for $\mathrm{CoSb}_{2.75} \mathrm{Sn}_{0.05} \mathrm{Te}_{0.20}$ consolidated at different temperatures, SEM micrographs of consolidated pellets, variable temperature X-ray diffraction data with Le Bail fits for $\mathrm{CoSb}_{2.75} \mathrm{Sn}_{0.05} \mathrm{Te}_{0.20}$, the alternative method for calculating $Z \bar{T}$ and plots of efficiency as a function of temperature difference (PDF).

\section{AUTHOR INFORMATION}

\section{Corresponding Author}

*E-mail for AVP: a.v.powell@reading.ac.uk

*E-mail for GM: min@cardiff.ac.uk

\section{Author Contributions}

The manuscript was written through contributions of all authors. All authors have given approval to the final version of the manuscript.

\section{Funding Sources}

UK Engineering and Physical Sciences Council (EP/K019767/1) 


\section{ACKNOWLEDGMENT}

The authors acknowledge financial support from the UK Engineering and Physical Sciences Council (EP/K019767/1). We wish to thank The University of Reading for access to the Chemical Analysis Facility and the Johnson Matthey (JM Technology Centre, Sonning Common, UK) for carrying out ICP measurements.

\section{REFERENCES}

(1) Bell, L. E. Cooling, Heating, Generating Power, and Recovering Waste Heat with Thermoelectric Systems. Science 2008, 321, 1457-1461.

(2) Majumdar, A. Thermoelectricity in Semiconductor Nanostructures. Science 2004, 303, 777778.

(3) Snyder, G. J.; Toberer, E. S. Complex Thermoelectric Materials. Nat. Mater. 2008, 7, 105114.

(4) Park, S. H.; Jin, Y.; Cha, J.; Hong, K.; Kim, Y.; Yoon, H.; Yoo, C.-Y.; Chung, I. HighPower-Density Skutterudite-Based Thermoelectric Modules with Ultralow Contact Resistivity Using Fe-Ni Metallization Layers. ACS Appl. Energy Mater. 2018, 1, 1603-1611.

(5) Chiwanga, S.; Tuley, R.; Placha, K.; Robbins, M.; Gilchrist, B.; Simpson, K. Automotive Power Harvesting/Thermoelectric Applications. In Thermoelectric Materials and Devices, Nandhakumar, I.; White, N. M.; Beeby, S., Eds.; Royal Society of Chemistry: 2016; pp 230-251. 
(6) Orr, B. G.; Akbarzadeh, A.; Lappas, P. Reducing Automobile $\mathrm{CO}_{2}$ Emissions with an Exhaust Heat Recovery System Utilising Thermoelectric Generators and Heat Pipes. SAE Technical Paper 2015-01-0051, 2015

(7) Mori, M.; Yamagami, T.; Oda, N.; Hattori, M.; Sorazawa, M.; Haraguchi, T. Current Possibilities of Thermoelectric Technology Relative to Fuel Economy. SAE Technical Paper 2009-01-0170, 2009

(8) Yang, J.; Stabler, F. R. Automotive Applications of Thermoelectric Materials. J. Electron. Mater. 2009, 38, 1245-1251.

(9) Hsu, C.-T.; Yao, D.-J.; Ye, K.-J.; Yu, B. Renewable Energy of Waste Heat Recovery System for Automobiles. J. Renewable Sustainable Energy 2010, 2, 013105.

(10). Ikoma, K.; Munekiyo, M.; Furuya, K.; Kobayashi, M.; Izumi, T.; Shinohara, K. in Thermoelectric Module and Generator for Gasoline Engine Vehicles, XVII International Conference on Thermoelectrics, 1998. Proceedings ICT 98., 24-28 May 1998; 1998; pp 464-467. (11) Bass, J. C.; Elsner, N. B.; Leavitt, F. A. Performance of the $1 \mathrm{~kW}$ Thermoelectric Generator for Diesel Engines, AIP Conf. Proc., AIP: 1994; pp 295-298.

(12) Zhang, Y.; Cleary, M.; Wang, X.; Kempf, N.; Schoensee, L.; Yang, J.; Joshi, G.; Meda, L. High-Temperature and High-Power-Density Nanostructured Thermoelectric Generator for Automotive Waste Heat Recovery. Energ. Convers. Manage. 2015, 105, 946-950.

(13) García-Cañadas, J.; Powell, A. V.; Kaltzoglou, A.; Vaqueiro, P.; Min, G. Fabrication and Evaluation of a Skutterudite-Based Thermoelectric Module for High-Temperature Applications. J. Electron. Mater. 2013, 42, 1369-1374. 
(14) LaGrandeur, J.; Crane, D.; Hung, S.; Mazar, B.; Eder, A. Automotive Waste Heat Conversion to Electric Power using Skutterudite, TAGS, PbTe and BiTe, Proceedings of the $25^{\text {th }}$ International Conference on Thermoelectrics, IEEE: 2006; pp 343-348.

(15) Yang, J. Potential Applications of Thermoelectric Waste Heat Recovery in the Automotive Industry.Proceedings of the $24^{\text {th }}$ International Conference on Thermoelectrics, 2005; pp 170-174.

(16) Gao, M.; Rowe, D. M. Ring-Structured Thermoelectric Module. Semicond. Sci. Technol. 2007, 22, 880 .

(17) Barnard, R. D. Thermoelectricity in Metals and Alloys. Halsted Press: 1972.

(18) Wood, C. Materials for Thermoelectric Energy Conversion. Rep. Prog. Phys. 1988, 51, 459.

(19) Guo, J. Q.; Geng, H. Y.; Ochi, T.; Suzuki, S.; Kikuchi, M.; Yamaguchi, Y.; Ito, S. Development of Skutterudite Thermoelectric Materials and Modules. J. Electron. Mater. 2012, 41, 1036-1042.

(20) Ochi, T.; Nie, G.; Suzuki, S.; Kikuchi, M.; Ito, S.; Guo, J. Q., Power-Generation Performance and Durability of a Skutterudite Thermoelectric Generator. J. Electron. Mater. 2014, 43, 2344-2347.

(21) Salvador, J. R.; Cho, J. Y.; Ye, Z.; Moczygemba, J. E.; Thompson, A. J.; Sharp, J. W.; Koenig, J. D.; Maloney, R.; Thompson, T.; Sakamoto, J.; Wang, H.; Wereszczak, A. A. Conversion Efficiency of Skutterudite-Based Thermoelectric Modules. Phys. Chem. Chem. Phys. 2014, 16, 12510-12520.

(22) Shi, X.; Yang, J.; Salvador, J. R.; Chi, M.; Cho, J. Y.; Wang, H.; Bai, S.; Yang, J.; Zhang, W.; Chen, L. Multiple-Filled Skutterudites: High Thermoelectric Figure of Merit through Separately Optimizing Electrical and Thermal Transports. J. Am. Chem. Soc. 2011, 133, 78377846. 
(23) Shi, X.; Salvador, J. R.; Yang, J.; Wang, H. Thermoelectric Properties of n-Type MultipleFilled Skutterudites. J. Electron. Mater. 2009, 38, 930-933.

(24) Shi, X.; Kong, H.; Li, C.-P.; Uher, C.; Yang, J.; Salvador, J. R.; Wang, H.; Chen, L.; Zhang, W. Low Thermal Conductivity and High Thermoelectric Figure of Merit in n-Type $\mathrm{Ba}_{\mathrm{x}} \mathrm{Yb}_{\mathrm{y}} \mathrm{Co}_{4} \mathrm{Sb}_{12}$ Double-Filled Skutterudites. Appl. Phys. Lett. 2008, 92, 182101.

(25) Prado-Gonjal, J.; Vaqueiro, P.; Nuttall, C.; Potter, R.; Powell, A. V. Enhancing the Thermoelectric Properties of Single and Double Filled p-Type Skutterudites Synthesized by an Up-Scaled Ball-Milling Process. J. Alloy. Comp. 2017, 695, 3598-3604.

(26) Liu, W.-S.; Zhang, B.-P.; Zhao, L.-D.; Li, J.-F. Improvement of Thermoelectric Performance of $\mathrm{CoSb}_{3-\mathrm{x}} \mathrm{Te}_{\mathrm{x}}$ Skutterudite Compounds by Additional Substitution of IVB-Group Elements for Sb. Chem. Mater. 2008, 20, 7526-7531.

(27) Rodriguez-Carvajal, J. FULLPROF: a Program for Rietveld Refinement and Pattern Matching Analysis. Abstracts of the Satellite Meeting on Powder diffraction of the XV Congress of the IUCr 1990, p. 127.

(28) Cowan, R. D. Pulse Method of Measuring Thermal Diffusivity at High Temperatures. $J$. Appl. Phys 1963, 34, 926-927.

(29) Kim, H.-S.; Gibbs, Z. M.; Tang, Y.; Wang, H.; Snyder, G. J. APL Materials, 2015, 3, 041506.

(30) Garcia-Canadas, J.; Min, G. Impedance Spectroscopy Models for the Complete Characterization of Thermoelectric Materials. J. Appl Phys. 2014, 116, 174510.

(31) García-Cañadas, J.; Min, G. Thermal Dynamics of Thermoelectric Phenomena from Frequency Resolved Methods. AIP Adv. 2016, 6, 035008. 
(32) Beltrán-Pitarch, B.; Prado-Gonjal, J.; Powell, A. V.; Ziolkowski, P.; García-Cañadas, J.

Thermal Conductivity, Electrical Resistivity, and Dimensionless Figure of Merit (ZT)

Determination of Thermoelectric Materials by Impedance Spectroscopy up to $250^{\circ}$ C. J. Appl. Phys 2018, 124, 025105.

(33) Sklad, A. C.; Gaultois, M. W.; Grosvenor, A. P. Examination of $\mathrm{CeFe}_{4} \mathrm{Sb}_{12}$ upon Exposure to Air: Is This Material Appropriate for Use in Terrestrial, High-Temperature Thermoelectric Devices? J. Alloys Compd. 2010, 505, L6-L9.

(34) Park, K.-H.; You, S.-W.; Ur, S.-C.; Kim, I.-H.; Choi, S.-M.; Seo, W.-S., High-Temperature Stability of Thermoelectric Skutterudite $\mathrm{In}_{0.25} \mathrm{Co}_{3} \mathrm{FeSb}_{12}$. J. Electron. Mater. 2012, 41, 10511056.

(35) Ni, J. E.; Case, E. D.; Schmidt, R. D.; Wu, C.-I.; Hogan, T. P.; Trejo, R. M.; Kirkham, M. J.; Lara-Curzio, E.; Kanatzidis, M. G. The Thermal Expansion Coefficient as a Key Design Parameter for Thermoelectric Materials and its Relationship to Processing-Dependent Bloating. J. Mater. Sci. 2013, 48, 6233-6244.

(36) Ravi, V.; Firdosy, S.; Caillat, T.; Brandon, E.; Van Der Walde, K.; Maricic, L.; Sayir, A. Thermal Expansion Studies of Selected High-Temperature Thermoelectric Materials. J. Electron. Mater. 2009, 38, 1433-1442.

(37) Sekine, C.; Shimaya, Y.; Shirotani, I.; Haen, P. Thermal Expansion of Filled Skutterudite Compound $\mathrm{SmRu}_{4} \mathrm{P}_{12}$. J Phys. Soc. Jpn. 2005, 74, 3395-3396.

(38) Oeschler, N.; Gegenwart, P.; Steglich, F.; Frederick, N.; Bauer, E.; Maple, M. Thermal Expansion of the Skutterudite Superconductor $\mathrm{PrOs}_{4} \mathrm{Sb}_{12}$. Acta Phys. Pol. A 2003, 34, 959-962. 
(39) Rogl, G.; Zhang, L.; Rogl, P.; Grytsiv, A.; Falmbigl, M.; Rajs, D.; Kriegisch, M.; Müller, H.; Bauer, E.; Koppensteiner, J. Thermal Expansion of Skutterudites. J. Appl. Phys. 2010, 107, 043507.

(40) Mott, N. F.; Jones, H. The theory of the properties of metals and alloys. Courier Corporation: 1958.

(41) Rogl, G.; Grytsiv, A.; Melnychenko-Koblyuk, N.; Bauer, E.; Laumann, S.; Rogl, P. Compositional Dependence of the Thermoelectric Properties of $\left(\mathrm{Sr}_{\mathrm{x}} \mathrm{Ba}_{\mathrm{x}} \mathrm{Yb}_{1-2 \mathrm{x}}\right)_{\mathrm{y}} \mathrm{Co}_{4} \mathrm{Sb}_{12}$ Skutterudites. J. Phys.: Condens. Matter 2011, 23, 275601.

(42) Goldsmid, H. J.; Sharp, J. W. Estimation of the Thermal Band Gap of a Semiconductor from Seebeck Measurements. J. Electron. Mater. 1999, 28, 869-872.

(43) Sharp, J. W.; Jones, E. C.; Williams, R. K.; Martin, P. M.; Sales, B. C. Thermoelectric Properties of $\mathrm{CoSb}_{3}$ and Related Alloys. J. Appl. Phys. 1995, 78, 1013-1018.

(44) Toprak, M. S.; Stiewe, C.; Platzek, D.; Williams, S.; Bertini, L.; Müller, E.; Gatti, C.; Zhang, Y.; Rowe, M.; Muhammed, M. The Impact of Nanostructuring on the Thermal Conductivity of Thermoelectric $\mathrm{CoSb}_{3}$. Adv. Funct. Mater. 2004, 14, 1189-1196.

(45) Romanjek, K.; Vesin, S.; Aixala, L.; Baffie, T.; Bernard-Granger, G.; Dufourcq, J. HighPerformance Silicon-Germanium-Based Thermoelectric Modules for Gas Exhaust Energy Scavenging. J. Electron. Mater. 2015, 44, 2192-2202.

(46) Hao, F.; Qiu, P.; Tang, Y.; Bai, S.; Xing, T.; Chu, H.-S.; Zhang, Q.; Lu, P.; Zhang, T.; Ren, D. High Efficiency $\mathrm{Bi}_{2} \mathrm{Te}_{3}$-Based Materials and Devices for Thermoelectric Power Generation between 100 and $300^{\circ}$ C. Energ. Environ. Sci. 2016, 9, 3120-3127. 
Table of Contents Graphic

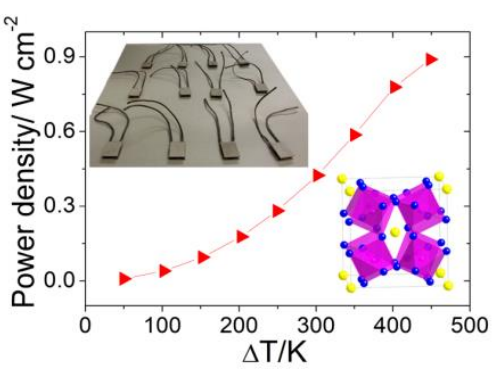

